\title{
Environmental Humidity Problem Identified
}

National Cancer Institute

\section{Source}

National Cancer Institute. Environmental Humidity Problem Identified. NCI Thesaurus.

Code C92061.

Device performance was affected by the humidity, or changes in humidity, of the environment in which it was used. 